\title{
A Real-World, Non-interventional Indian Study Evaluating Intensive Plant-Based Butter Moisturizing Cream in Psoriasis
}

\author{
Hemangi Rajiv Jerajani · Jayakar Thomas · Alka Gupta • \\ Gurram Narasimha Rao Netha - Ranju Chawla - Rashid Shaikh · \\ Ravindra Babu • Irene Williams • Prajakta Talathi - Suyog C. Mehta • \\ Rajan Mittal $\cdot$ Shivani Acharya $\cdot$ Sujeet N. Charugulla
}

Received: April 11, 2019 / Published online: June 14, 2019

(C) The Author(s) 2019

\section{ABSTRACT}

Introduction: Psoriasis is estimated to affect $0.44-2.8 \%$ of the Indian population. Moisturizers are a key adjuvant psoriasis treatment strategy, but data regarding their effectiveness, safety and compliance pattern in an Indian context are lacking. Hence, this real-world study on an intensive plant-based butter

Enhanced Digital Features To view enhanced digital features for this article go to https://doi.org/10.6084/ m9.figshare.8192303.

Electronic supplementary material The online version of this article (https://doi.org/10.1007/s13555019-0307-0) contains supplementary material, which is available to authorized users.

H. R. Jerajani

MGM Medical College and Hospital, Mumbai, India

J. Thomas

JT Skin Care Centre, Chennai, India

A. Gupta

Gupta Skin Clinic, New Delhi, India

G. N. R. Netha

Gandhi Medical College and Government Hospital, Hyderabad, India

R. Chawla

Dr. Ranju Chawla's Skin Clinic, New Delhi, India

R. Shaikh

Rehmat Clinic and Nursing Home, Thane, India moisturizing cream (Venusia ${ }^{\circledR}$ Max) was conducted among Indian patients with psoriasis.

Methods: This was an observational, patientreported outcomes (PRO) study in patients with psoriasis aged 18-75 years who were prescribed the cream in routine clinical practice, as per clinician's discretion, over 4 weeks. The primary outcome measure was improvement from baseline in quality of life assessed using the Dermatology Quality of Life Index (DLQI) at 4 weeks of the study period. The secondary outcome measures were improvement in dryness using the Dry Skin/Ichthyosis Area and Severity Index (DASI) score at 4 weeks, safety and compliance. The DLQI and DASI scores were recorded by the clinicians at baseline and after 2 (optional) and 4 weeks of starting the

R. Babu

Raga's Skin Care Clinic, Bengaluru, India

I. Williams

Dermicos Skin Clinic, Chennai, India

P. Talathi

Skin Space Clinic, Mumbai, India

S. C. Mehta · R. Mittal · S. Acharya .

S. N. Charugulla $(\bowtie)$

Dr. Reddy's Laboratories Limited, Hyderabad, India

e-mail: sujeetnc@drreddys.com 
cream. Safety was assessed throughout the study.

Results: The study included 400 patients from 9 outpatient dermatology centers across India. Of 400 patients, 384 completed the study. A significant reduction in both the mean DLQI score $(66.7 \% ; p<0.001)$ and mean DASI score $(84.6 \% ; p<0.001)$ was observed at week 4 after starting the cream vs. baseline in the overall population. Overall, the cream showed a good safety and compliance profile during the study period. There were no serious adverse events or deaths.

Conclusions: The evidence from the PRO study suggests that use of the intensive plant-based butter moisturizing cream in a real-world scenario has a noticeable impact on improving the quality of life and reducing the skin dryness associated with psoriasis over 4 weeks. The moisturizing cream may serve as a valuable adjuvant treatment option for the management of psoriasis.

Trial Registration Number: CTRI/2017/03/ 008023.

Funding: Dr. Reddy's Laboratories Ltd.

Keywords: Compliance; Moisturizer; Psoriasis; Quality of life; Real world; Safety

\section{INTRODUCTION}

Psoriasis is a chronic autoimmune condition predominantly linked to genetic factors and to a lesser extent to environmental factors [1]. According to various hospital-based studies, the prevalence of psoriasis in India varies from 0.44 to $2.8 \%$, and it is more common in males than females $[2,3]$. The disease is characterized by the presence of well-defined erythematous plaques with silvery scales that arise most commonly on the extensor surfaces of the elbows, knees, lumbosacral region and scalp $[4,5]$. Various forms of psoriasis include psoriasis vulgaris, guttate form, erythrodermic form, pustular and palmoplantar psoriasis [2, 4, 5]. The clinical classification of the disease ranges from mild, wherein skin plaques cover $<3 \%$ of the body surface area, to moderate $(3-10 \%$ of body surface area affected) and severe ( $>10 \%$ of body surface area affected) [6]. The impact of psoriasis on a patient primarily depends on the affected areas of the patient's body [6]. The disease is incurable and requires lifelong control to minimize the development of skin lesions and to relieve existing symptoms [7]. Numerous topical and systemic therapies are available for the disease, and the selection of therapy depends primarily on the severity of disease, cost of therapy, adverse-effect profile of the therapeutic agent, patient preference and availability of the treatment agents (Fig. 1) $[4,6,8,9]$.

Topical agents remain the standard of care for treating mild-to-moderate psoriasis and are used as an adjuvant with ultraviolet (UV) light or systemic agents in moderate-to-severe cases $[8,10-12]$. American and European guidelines highly recommend topical agents such as vitamin D analogs, corticosteroid monotherapy or combination therapy based on consistent, highquality clinical evidence $[6,13]$. The presence of dry skin in psoriasis, in addition to being distressing to patients, can further cause adverse consequences such as fissures and infections [6]. These, in turn, contribute to a decreased quality of life (QoL), reduced productivity, lost work days, increased incidence of comorbidities and social isolation in some cases. Hence, the treating agents should be able to improve upon the patient's QoL [6, 14, 15].

In psoriasis, breakdown of the skin barrier leads to exaggeration of inflammation along with release of proinflammatory mediators [16]. Therefore, moisturizers that have established compatibility with topical agents serve as a promising modality to improve the signs and symptoms of dry skin [17, 18]. They help maintain the hydration and overall integrity of the skin. The improvement in the skin barrier function and the hydration status of the stratum corneum makes the epidermis more resistant to external irritants [19]. Though many internal guidelines are available, there is no well-defined Indian guideline for the effective management of the disease, and data regarding the use of moisturizers and their effectiveness are lacking.

The cream investigated in this study is an intensive moisturizing cream with a 


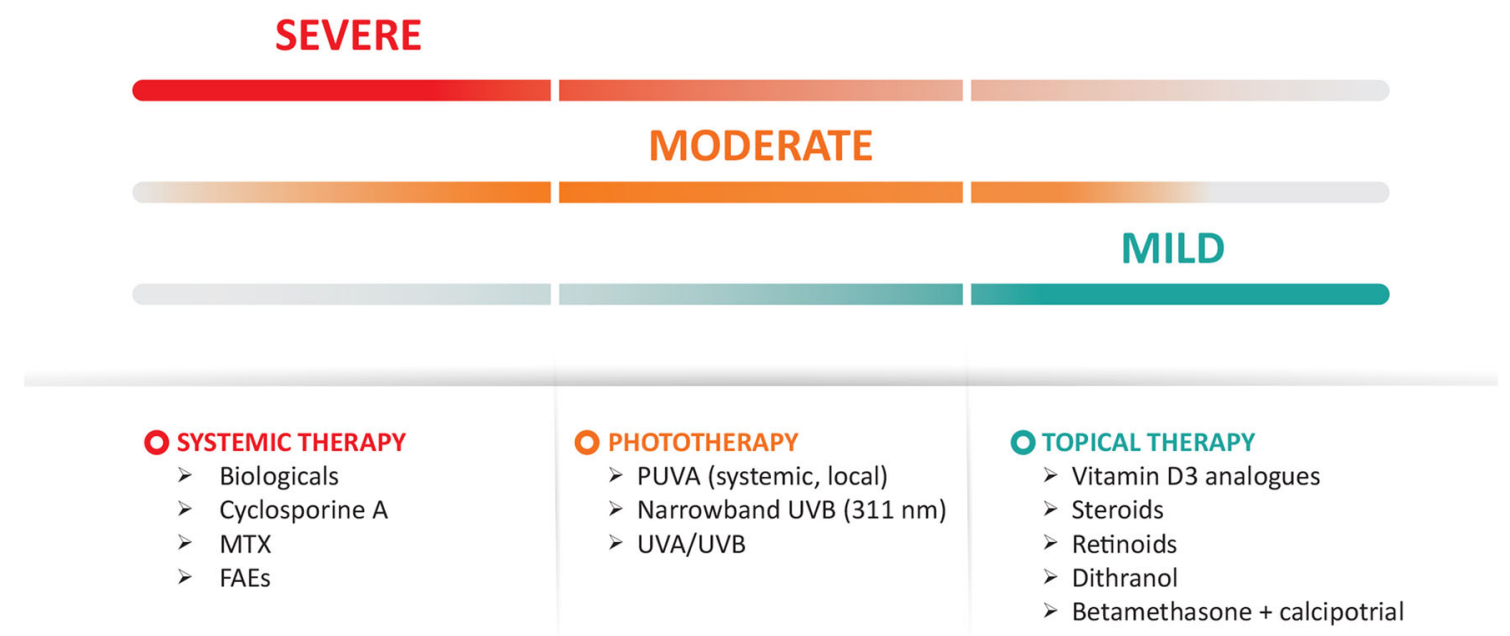

Fig. 1 Various topical and systemic therapies available for the management of psoriasis [6]. FAE fumaric acid ester; $M T X$ methotrexate; PUVA psoralen + UVA treatment; $U V A$ ultraviolet A; $U V B$ ultraviolet B. Narrow band UVB

combination of plant-based butters (shea, aloe, mango, cocoa); it provides hydration and softens and heals dry skin. It previously demonstrated an improvement in skin hydration in patients with dry skin conditions and had a good safety profile [20]. Our study aimed to contribute to the real-world evidence of the effectiveness and safety of the intense moisturizing cream in the overall management of Indian patients with psoriasis.

\section{METHODS}

This was a real-world, multicentric, non-interventional, observational study conducted in outpatient dermatology departments/clinics across various regions of India.

\section{Study Participants}

Adult male and female patients with psoriasis aged between 18 and 75 years and for whom the physician decided to prescribe the intensive plant-based butter moisturizing cream for psoriasis were enrolled in the study. Patients with known hypersensitivity to any ingredient or component of the cream were excluded from the study.

\section{Compliance with Ethics Guidelines}

The study was approved by the independent/ institutional ethics committee(s) at all the participating centers and was conducted in compliance with the International Conference on Harmonisation (ICH) E6 Guideline for Good Clinical Practice (GCP), the Declaration of Helsinki (October 1996) and applicable country laws [Indian Council of Medical Research (ICMR) regulations]. Please see the supplementary material for a complete list of ethics committees. The patients received a detailed explanation of the trial and were further encouraged to raise any queries about the study. Written informed consent was obtained from all patients before enrollment in the study, which was registered on the Clinical Trials Registry of India (CTRI): CTRI/2017/03/008023; registered on: 07/03/2017).

\section{Study Treatments}

Patients who were prescribed the intensive plant-based butter moisturizing cream (Venusia ${ }^{\circledR}$ Max cream, Dr. Reddy's Laboratories Ltd., India) for a 4-week period at the physician's discretion were enrolled. Patients were allowed to continue other concomitant medications. The Venusia ${ }^{\circledR}$ Max cream consists of shea 
butter, aloe butter, mango butter and cocoa butter along with propylene glycol, glycerin, glycol, emulsifying wax, cyclomethicone, dimethicone, cetyl alcohol, stearic acid, ethyl paraben, propyl paraben, disodium edetate, zinc oxide and fragrance.

\section{Study Procedures}

A detailed medical history of all the enrolled patients was obtained, and the clinical examination was carried out as per routine clinical practice by the clinicians at baseline. The patient-reported effectiveness and compliance outcome data for the cream were recorded by the clinicians at baseline and after 2 weeks (optional) and 4 weeks of introducing the cream. The effectiveness of the moisturizing cream in improving the QoL was recorded by the Dermatology Life Quality Index (DLQI) Questionnaire. The DLQI questionnaire is a tenitem validated questionnaire for assessing QoL in patients with dermatologic conditions $[21,22]$. The DLQI scoring was used to assess the effect of psoriasis on the patient's QoL: no effect at all on patient's life (score 0-1), a small effect on patient's life (score 2-5), a moderate effect on patient's life (score 6-10), a very large effect on patient's life (score 11-20) and an extremely large effect on patient's life (21-30). The effect of the cream regarding the reduction in dryness associated with psoriasis was recorded by the Dry Skin/Ichthyosis Area and Severity Index (DASI) score. DASI scores of $0-4$ are considered for each body region separately. Assessed areas included the head and neck ( $10 \%$ of total area), upper extremities (20\% of total area), trunk (30\% of total area) and lower extremities (40\% of total area). The scaling/roughness/fissure and cracks were graded as absent (0), slight (1), moderate (2), severe (3) and very severe (4) with eczema. The DASI score was calculated as the sum of the four body regions [23].

\section{Study Outcomes}

The primary outcome of the study was to assess the reduction in DLQI scores from baseline at the end of the 4-week study period. Secondary outcomes were the reduction in DASI score at the end of 4 weeks, compliance with and safety of the cream. Safety assessment was based on spontaneous reports generated by the clinician.

\section{Statistical Analysis}

To evaluate the role of the moisturizer in improvement of scores as measured by the Quality of Life (DLQI) questionnaire at 4 weeks from baseline, we required 400 subjects with the assumptions of margin of error $=5 \%$, confidence level $=95 \%$ and percentage of mean change from baseline $=50 \%$. Therefore, a total of 400 subjects were proposed.

Data from all the study centers were pooled for analysis. The data were analyzed using $\mathrm{R}$ software version 3.2.3. Continuous variables are presented as mean and standard deviation. Categorical variables are presented as count and percent. Comparison of means between two time points was made using the paired $t$-test. Comparison of means among three time points was made using one-way repeated measure analysis of variance (ANOVA). $p<0.05$ was considered statistically significant.

\section{RESULTS}

\section{Demographics and Patient Characteristics}

A total of 400 patients were enrolled from 9 study centers, of whom 16 were discontinued since they were lost to follow-up. Among the 384 patients completing the study, 179 completed the week-2 follow-up, and 384 patients completed the week-4 follow-up. Demographic details for all the enrolled patients are presented in Table 1 . The frequency of cream application was decided by the treating physician based on patient characteristics. The details concerning the concomitant medication use by the patients are presented in the supplementary material (Tables S1 and S2). A total of 151 patients were on moisturizing cream alone without any concomitant therapy (37.75\%). 
Table 1 Patients characteristics and concomitant treatment at baseline

\begin{tabular}{ll}
\hline Patient characteristics & Mean \pm SD/count (\%) \\
\hline Sex & $203(50.8)$ \\
Male & $197(49.2)$ \\
Female & $43.9 \pm 13.9$ \\
Age (years) $(\boldsymbol{n}=\mathbf{4 0 0})$ & \\
Smoking & $320(80.0)$ \\
Never & $37(9.3)$ \\
Former & $42(10.5)$ \\
Current & $1(0.25)$ \\
NA & \\
Alcohol & $92(23.0)$ \\
Yes & $307(76.8)$ \\
No & $1(0.3)$ \\
NA & $1(0.3)$ \\
Clinically relevant pre-existing condition (other than \\
psoriasis) & \\
Cardiovascular disease & $12(3.0)$ \\
Diabetes & $24(6.0)$ \\
Hypertension & $43(10.8)$ \\
Lower urinary tract symptoms & $2(0.5)$ \\
Hypothyroidism & $1(0.3)$ \\
Thyroid & $2(0.5)$ \\
Umbilical hernia & \\
No & \\
NA & \\
&
\end{tabular}

Has the patient been newly diagnosed with psoriasis?

$\begin{array}{ll}\text { Yes } & 114(28.5) \\ \text { No } & 271(67.75) \\ \text { NA } & 15(3.75)\end{array}$

Severity of psoriasis

Mild

$127(31.75)$

Moderate

$220(55.0)$

Severe

$49(12.25)$
Table 1 continued

\begin{tabular}{lc}
\hline Patient characteristics & \multicolumn{1}{l}{ Mean \pm SD/count (\%) } \\
\hline NA & $4(1)$ \\
Type of treatment received for psoriasis \\
Systemic therapy & $35(8.75)$ \\
Topical therapy & $335(83.75)$ \\
NA & $30(7.5)$ \\
Has the patient received treatment with moisturizers \\
and emollients previously? \\
Yes & $294(73.5)$ \\
No & $96(24)$ \\
NA & $10(2.5)$ \\
\hline
\end{tabular}

\section{Efficacy Outcomes}

Tables 2 and 3 show the descriptive data for the DLQI and DASI scores. The post-treatment scores at week 2 and week 4 for DLQI and DASI were significantly lower than the baseline scores $(p<0.0001)$. The percentage reductions from baseline in DLQI scores and DASI scores are presented in Figs. 1 and 2, respectively.

\section{Dermatology Life Quality Index (DLQI) Score}

Based on the DLQI scores at baseline $(n=400)$, psoriasis significantly affected patients' life with $12 \%$ and $29 \%$ of patients reporting an extremely large and very large effect on their life. After starting the intensive plant-based butter moisturizing cream at 4 weeks $(n=383)$ only $0.5 \%$ and $15.9 \%$ of patients had an extremely large effect and very large effect on life. Significant $(p<0.0001)$ improvement (reduction in mean DLQI scores) was observed at both week-2 and week-4 follow-ups. All individual items of the DLQI questionnaire also showed a significant reduction from baseline over a period of 4 weeks $(p<0.001)$. A $66.6 \%$ and $54.4 \%$ reduction was observed in the mean DLQI score for patients with moderate and severe psoriasis, 
Table 2 Effect of the cream on DLQI scores over the treatment period

\begin{tabular}{llll}
\hline & $\begin{array}{l}\text { Baseline }(\boldsymbol{n}=\mathbf{4 0 0}) \\
\text { Mean }( \pm \text { SD) }\end{array}$ & $\begin{array}{l}\text { Week 2 }(\boldsymbol{n}=\mathbf{1 7 8}) \\
\text { Mean }(\mathbf{\pm} \text { SD })\end{array}$ & $\begin{array}{l}\text { Week 4 }(\boldsymbol{n}=\mathbf{3 8 3}) \\
\text { Mean }(\mathbf{\pm} \text { SD })\end{array}$ \\
\hline DLQI scores & $10.5(7.44)$ & $5.4(4.29)$ & $4.2(5.09)$ \\
\% Reduction change in DLQI scores & - & $29.8 \%$ & $63.0 \%$ \\
$\begin{array}{l}p \text { value (vs. baseline) } \\
\text { DLQI score according to psoriasis severity }\end{array}$ & - & $<0.001$ & $<0.001$ \\
Mild & $6.3(4.52)$ & & \\
Moderate & $11.4(7.47)$ & $5.0(4.51)$ & $2.7(3.2)$ \\
Severe & $17.1(7.12)$ & $5.4(4.22)$ & $4.2(5.25)$ \\
$p$ value (vs. baseline for all psoriasis severity) & & $6.2(4.21)$ & $7.9(6.07)$ \\
\hline
\end{tabular}

Table 3 Effect of the cream on DASI scores over the treatment period

\begin{tabular}{|c|c|c|c|}
\hline & $\begin{array}{l}\text { Baseline }(n=399) \\
\text { Mean }( \pm \text { SD })\end{array}$ & $\begin{array}{l}\text { Week } 2(n=178) \\
\text { Mean }( \pm \text { SD })\end{array}$ & $\begin{array}{l}\text { Week } 4(n=384) \\
\text { Mean }( \pm \text { SD })\end{array}$ \\
\hline DLQI scores & $430.5(255.5)$ & $207.3(142.1)$ & $150.3(159.8)$ \\
\hline \% Reduction change in DASI scores & - & $73.5 \%^{\mathrm{a}}$ & $84.6 \%^{\mathrm{a}}$ \\
\hline \multirow[t]{2}{*}{$p$ value (vs. baseline) } & - & $<0.001$ & $<0.001$ \\
\hline & $\begin{array}{l}\text { Baseline }(n=399) \\
\text { Mean }( \pm \text { SD) }\end{array}$ & $\begin{array}{l}\text { Week } 4(n=384) \\
\text { Mean }( \pm \text { SD) }\end{array}$ & $\begin{array}{l}\text { Percentage mean } \\
\text { change (week } 4 \text { vs. } \\
\text { baseline) (\%) }\end{array}$ \\
\hline \multicolumn{4}{|l|}{ DASI score according to psoriasis severity } \\
\hline Mild & $257.2(179.79)$ & $78.9(79.53)$ & $69.6 \%^{\mathrm{a}}$ \\
\hline Moderate & $465.0(213.95)$ & $156.5(163.05)$ & $73.9 \%^{\mathrm{a}}$ \\
\hline Severe & $734.3(251.33)$ & $300.4(187.17)$ & $86.4 \%^{\mathrm{a}}$ \\
\hline$p$ value (vs. baseline for all psoriasis severity) & - & $<0.001$ & $<0.001$ \\
\hline
\end{tabular}

${ }^{a}$ Values are mean of difference in DASI score for individual patients

respectively, compared with baseline, at the 4 th week of the study (Table 2; Fig. 3).

\section{Dry Skin/Ichthyosis Area and Severity Index (DASI) Score Assessment}

The mean DASI score significantly reduced to $84.6 \%$ at the 4 th week $(n=384)$ after starting the intensive plant-based butter moisturizing cream compared with baseline $(n=399)$. A significant reduction in DASI scores was observed at the 4th week compared with baseline, with a reduction of $69.6 \%, 73.9 \%$ and $86.4 \%$ reported in patients with mild, moderate and severe disease, respectively (Table 3 ).

\section{Compliance Assessment}

It was observed that $96.6 \%$ and $92.1 \%$ of patients, as assessed at the 2nd and 4th week, 


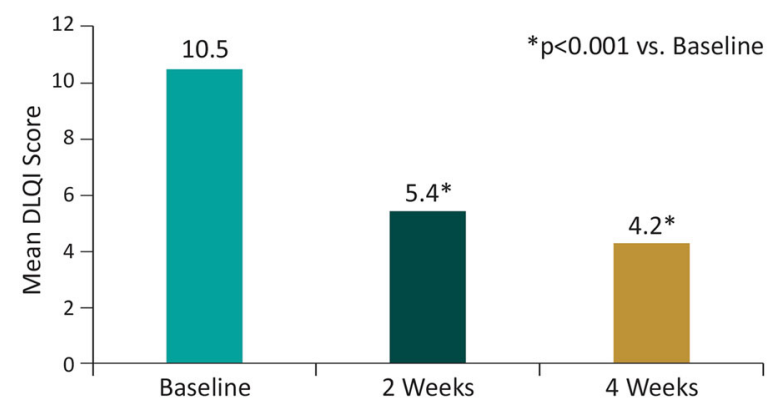

Fig. 2 Effect of treatment with cream on DLQI scores over study period

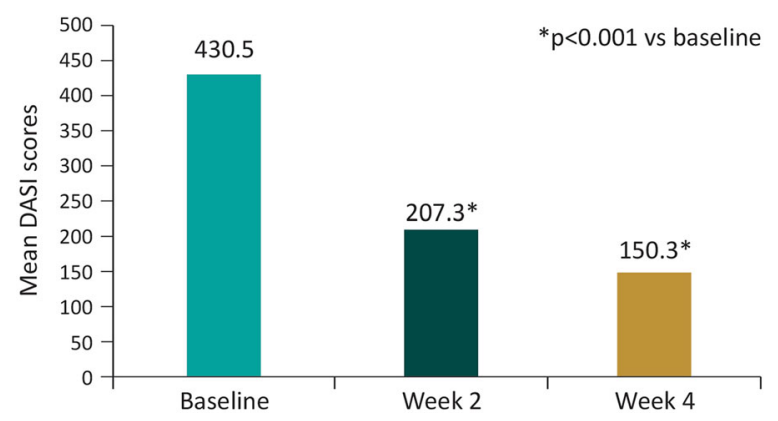

Fig. 3 Effect of treatment with cream on DASI scores over study period

respectively, had used the intensive plant-based butter moisturizing cream as instructed by the physician (Table 4).

\section{Safety Outcomes}

A total of 8 out of 400 patients reported an adverse event (AE) in the study. The majority of AEs were mild to moderate in severity and did

Table 4 Compliance with the cream over the study period

\begin{tabular}{lccccr}
\hline $\begin{array}{l}\text { Usage of moisturizer } \\
\text { as per the physician's } \\
\text { instruction }\end{array}$ & $\begin{array}{l}\text { Week } 2 \\
(\boldsymbol{n}=\mathbf{1 7 9})\end{array}$ & & \multicolumn{2}{l}{$\begin{array}{l}\text { Week } 4 \\
(\boldsymbol{n}=\mathbf{3 8 4})\end{array}$} \\
\cline { 2 - 3 } & $\begin{array}{l}\text { No. of } \\
\text { patients }\end{array}$ & & $\begin{array}{l}\text { No. of } \\
\text { patients }\end{array}$ & $\%$ \\
\hline Yes & 173 & 96.6 & 350 & 91.1 \\
Most days & 3 & 1.7 & 8 & 2.1 \\
A few days & 0 & 0 & 2 & 0.5 \\
Missing & 3 & 1.7 & 24 & 6.3 \\
\hline
\end{tabular}

Table 5 Frequency of adverse events occurring in subjects (all causalities)

\begin{tabular}{ll}
\hline System organ class-preferred term & $\begin{array}{l}\text { All patients } \\
(\boldsymbol{n}=\mathbf{4 0 0})\end{array}$ \\
\hline Overall total & $8(9)[2.0 \%]$ \\
Skin and subcutaneous tissue disorders & \\
Itching and darkening of skin & $1(1)[0.25 \%]$ \\
Soothing, itching & $1(1)[0.25 \%]$ \\
Post-inflammatory hyperpigmentation & $1(1)[0.25 \%]$ \\
to psoralen and ultraviolet A & \\
(PUVA) therapy & $1(1)[0.25 \%]$ \\
New lesions & $1(1)[0.25 \%]$ \\
Exacerbation of lesions & $1(1)[0.25 \%]$ \\
Nervous system disorders & $1(2)[0.25 \%]$ \\
Mild headache & $1(1)[0.25 \%]$ \\
Infections and infestations & \\
Mild fever & Fever
\end{tabular}

$N$ number of subjects studied, [percentage of subjects with adverse events], (number of adverse events)

not require treatment interruption. Nine adverse events occurred in the study, of which five were categorized under the skin and subcutaneous tissue disorder system organ class, three to the infection and infestation class and one to nervous system disorders. There was no age and/or gender predilection for AEs in the study. No serious AEs or deaths occurred during the study (Table 5).

\section{DISCUSSION}

As the chronic condition of psoriasis has a detrimental effect on patients' overall QoL, it is crucial that the treating agents should have a positive impact on the patients' QoL. The impact on patients' social and personal life is thus a crucial factor in determining the choice of therapy [24]. In a placebo-controlled study conducted by Syed et al. among 60 patients with psoriasis, to evaluate the clinical 
effectiveness and tolerance of aloe vera extract $(0.5 \%)$ in a hydrophilic cream, the Psoriasis Area and Severity Index (PASI) score was used. Patients were randomized to receive either the hydrophilic cream or matching placebo. Results from the study showed statistically significant lowering in mean PASI score in the aloe-treated group compared with the placebo group (9.3-2.2) [25]. To check the impact on QoL, our study used the DLQI score. The validated DLQI is predominantly a patient-reported questionnaire covering every aspect of a patient's life and provides more information than other methods regarding the outcomes of the treatment modality $[24,26]$. The findings from our study based on DLQI assessment showed mean DLQI scores were significantly reduced by $63 \%$ at the 4 th week $(p<0.001)$ after introducing the cream compared with baseline. The study results also showed an improvement in skin dryness associated with psoriasis as evaluated by the DASI score: the mean DASI score significantly decreased by $84.6 \%(p<0.001) 4$ weeks after introducing the cream compared with baseline. These improvements in skin dryness results were in line with the results obtained from a 4-week study conducted among 30 patients with mild-to-moderate plaque psoriasis [27].

Clinical studies on one of the constituents of our formulation, cocoa, which contains a mixture of bioactive components, have shown its tremendous potential to treat and prevent skin disease [28]. A study conducted among 12 adult patients with psoriasis assessed the effectiveness of a plant-based preparation containing olive oil, tea tree oil and cocoa butter. Treatment success was determined by the PASI score, and a PASI score reduction of $>75 \%$ was observed in $83 \%$ of patients, proving the cocoa-based formulation's effective in the management of psoriasis [29]. In addition to the effectiveness and safety of the treatment agent, another key factor influencing the success of a treatment strategy in chronic conditions is the adherence or compliance rate [30]. Among the several factors involved in poor patient compliance, patient's perception of therapy being not aggressive or effective is crucial. Additionally, a good safety profile, i.e., less frequent occurrence of adverse events by a primary therapeutic agent, leads to good compliance in patients [31]. Hence, a safe and tolerable treatment with a good patient adherence rate can boost the success of chronic disease therapy. Our plantbased butter moisturizing cream in addition to having a favorable safety profile had a good compliance profile similar to compliance results obtained in the study by Syed et al. using an aloe vera-based cream [25]. Considering all the benefits offered by the intensive plant-based butter moisturizing cream for the psoriasis condition, we suggest further exploration of the use of an intense moisturizing preparation as an adjuvant therapy in the Indian population with psoriasis. Although our present effort had no comparator and was observational in nature, the real-life clinical general practice picture from various regions of India was duly captured. We acknowledge certain limitations of the study, i.e., non-evaluation of the consequence of continuing anti-psoriatic agents; short duration of follow-up for a chronic condition such as psoriasis; non-assessment of the PASI score and various confounding factors affecting the efficacy response. We sincerely believe that future controlled comparative trials will remediate the above-mentioned limitations and reinforce the usefulness of the cream for the management of psoriasis in an Indian scenario.

\section{CONCLUSIONS}

Based on the real-world evidence, generated from the study, an intense moisturizing cream can be considered a valuable adjuvant therapy for efficient management of psoriasis in India.

\section{ACKNOWLEDGEMENTS}

Funding. Sponsorship for this study and article processing charges was provided by Dr. Reddy's Laboratories Ltd. All authors had full access to all of the data in this study and take complete responsibility for the integrity of the data and accuracy of the data analysis. 
Medical writing, editorial and other assistance. Editorial assistance in the preparation of this article was provided by Ms. Yukti Singh from BioQuest Solutions Pvt Ltd. Support for this assistance was funded by Dr. Reddy's Laboratories Ltd.

Authorship. All named authors meet the International Committee of Medical Journal Editors (ICMJE) criteria for authorship for this article, take responsibility for the integrity of the work as a whole and have given their approval for this version to be published.

Disclosures. Suyog C. Mehta is a medical pharmacologist, part of the Medical Affairs team of and employee of Reddy's Laboratories Ltd. Sujeet N. Charugulla is a medical pharmacologist, part of the Medical Affairs team and employee of Dr. Reddy's Laboratories Ltd. Rajan Mittal is a medical pharmacologist, part of the Medical Affairs team and employee of Dr. Reddy's Laboratories Ltd. Shivani Acharya is a medical pharmacologist, part of the Medical Affairs Team and employee of Dr. Reddy's Laboratories Ltd. Hemangi Rajiv Jerajani received remuneration from Dr. Reddy's Laboratories Ltd. for conduct of the clinical study. Jayakar Thomas received remuneration from Dr. Reddy's Laboratories Ltd. for conduct of the clinical study. Alka Gupta received remuneration from Dr. Reddy's Laboratories Ltd. for conduct of the clinical study. Narasimha Rao Netha G received remuneration from Dr. Reddy's Laboratories Ltd. for conduct of the clinical study. Ranju Chawla received remuneration from Dr. Reddy's Laboratories Ltd. for conduct of the clinical study. Rashid Shaikh received remuneration from Dr. Reddy's Laboratories Ltd. for conduct of the clinical study. Ravindra Babu received remuneration from Dr. Reddy's Laboratories Ltd. for conduct of the clinical study. Irene Williams received remuneration from Dr. Reddy's Laboratories Ltd. for conduct of the clinical study. Prajakta Talathi received remuneration from Dr. Reddy's Laboratories Ltd. for conduct of the clinical study.

Compliance with Ethics Guidelines. The study was approved by the Independent/
Institutional Ethics Committee(s) at all the participating centers and was conducted in compliance with the International Conference on Harmonisation (ICH) E6 Guideline for Good Clinical Practice (GCP), the Declaration of Helsinki (October 1996) and applicable country laws [Indian Council of Medical Research (ICMR) regulations].

Data Availability. The manuscript has no associated data or the data will not be deposited.

Open Access. This article is distributed under the terms of the Creative Commons Attribution-NonCommercial 4.0 International License (http://creativecommons.org/licenses/ by-nc/4.0/), which permits any noncommercial use, distribution, and reproduction in any medium, provided you give appropriate credit to the original author(s) and the source, provide a link to the Creative Commons license, and indicate if changes were made.

\section{REFERENCES}

1. Kuchekar AB, Pujari RR, Kuchekar SB, Dhole SN, Mule PM. Psoriasis: a comprehensive review. Int J Pharm Life Sci. 2011;2:857-77.

2. Dogra S, Yadav S. Psoriasis in India: prevalence and pattern. Indian J Dermatol Venereol Leprol. 2010;76:595-601.

3. Di Meglio P, Villanova F, Nestle FO. Psoriasis. Cold Spring Harb Perspect Med. 2014;4:1-30.

4. Witman PM. Topical therapies for localized psoriasis. Mayo Clin Proc. 2001;76:943-9.

5. McCormick T, Ayala-Fontanez N, Soler D. Current knowledge on psoriasis and autoimmune diseases. Psoriasis (Auckl). 2016;6:7-32.

6. Murphy G, Reich K. In touch with psoriasis: topical treatments and current guidelines. J Eur Acad Dermatol Venereol. 2011;25:3-8.

7. Jacobi A, Mayer A, Augustin M. Keratolytics and emollients and their role in the therapy of psoriasis: a systematic review. Dermatol Ther (Heidelb). 2015;5:1-18. 
8. Kim WB, Jerome D, Yeung J. Diagnosis and management of psoriasis. Can Fam Physician. 2017;63:278-85.

9. Schaarschmidt M-L. Patient preferences for psoriasis treatments. Arch Dermatol. 2011;147:1285.

10. Mason AR, Mason JM, Cork MJ, Hancock H, Dooley G. Topical treatments for chronic plaque psoriasis of the scalp: a systematic review. Br J Dermatol. 2013;169:519-27.

11. Weigle N, McBane S. Psoriasis. Am Fam Physician. 2013;87:626-33.

12. Torsekar R, Gautam M. Topical therapies in psoriasis. Indian Dermatol Online J. 2017;8:235-45.

13. Menter A, Korman NJ, Elmets CA, Feldman SR, Gelfand JM, Gordon KB, et al. Guidelines of care for the management of psoriasis and psoriatic arthritis. Section 3. Guidelines of care for the management and treatment of psoriasis with topical therapies. J Am Acad Dermatol. 2009;60:643-59.

14. Feldman SR, Goffe B, Rice G, Mitchell M, Kaur M, Robertson D, et al. The challenge of managing psoriasis: unmet medical needs and stakeholder perspectives. Am Health Drug Benefit. 2016;9:504-13.

15. Bhosle MJ, Kulkarni A, Feldman SR, Balkrishnan R. Quality of life in patients with psoriasis. Health Qual Life Outcomes. 2006;4:1-7.

16. Luger T, Seite S, Humbert P, Krutmann J, Triller R, Dréno B. Recommendations for adjunctive basic skin care in patients with psoriasis. Eur J Dermatol. 2014;24:194-200.

17. Bikowski J. The use of therapeutic moisturizers in various dermatologic disorders. Cutis. 2001;68:3-11.

18. Held E, Sveinsdóttir S, Agner T. Effect of long-term use of moisturizer on skin hydration, barrier function and susceptibility to irritants. Acta Derm Venereol. 1999;79:49-51.

19. Sarkar R, Chugh S, Bansal S. General measures and quality of life issues in psoriasis. Indian Dermatol Online J. 2016;7:481-8.

20. Mittal R, Madhusudan B, Soni MK. To study the efficacy of a moisturizing cream, Venusia max, on TEWL and skin hydration in women with dry skin. In: Poster presented at: 41st national conference of Indian Association of Dermatologists,
Venereologists and Leprologists (IADVL), DERMACON 2013; Jan 24 2012-Jan 27 2013, Gujarat.

21. Basra MK, Fenech R, Gatt RM, Salek MS, Finlay AY. The Dermatology Life Quality Index 1994-2007: a comprehensive review of validation data and clinical results. Br J Dermatol. 2008;159(5):997-1035.

22. Hongbo Y, Thomas CL, Harrison MA, Salek MS, Finlay AY. Translating the science of quality of life into practice: what do dermatology life quality index scores mean? J Investig Dermatol. 2005;125(4):659-64.

23. Vocks E, Plötz SG, Ring J. The Dyshidrotic Eczema Area and Severity Index-a score developed for the assessment of dyshidrotic eczema. Dermatology. 1999;198(3):265-9.

24. Torres RAT, da Silva SA, Magalhaes RF, Morcillo AM, Velho PENF. Comparison of quality of life questionnaires and their correlation with the clinical course of patients with psoriasis. An Bras Dermatol. 2011;86:45-9.

25. Syed TA, Ahmad SA, Holt AH, Ahmad SA, Ahmad $\mathrm{SH}$, Afzal M. Management of psoriasis with aloe vera extract in a hydrophilic cream: a placebocontrolled, double-blind study. Trop Med Int Health. 1996;1:505-9.

26. Jacobson CC, Kimball AB. Rethinking the Psoriasis Area and Severity Index: the impact of area should be increased. Br J Dermatol. 2004;151:381-7.

27. Draelos ZD. Moisturizing cream ameliorates dryness and desquamation in participants not receiving topical psoriasis treatment. Cutis. 2008;82:211-6.

28. Scapagnini G, Davinelli S, Di Renzo L, De Lorenzo A, Olarte HH, Micali G, et al. Cocoa bioactive compounds: significance and potential for the maintenance of skin health. Nutrients. 2014;6:3202-13.

29. Michalsen A, Eddin O, Salama A. A case series of the effects of a novel composition of a traditional natural preparation for the treatment of psoriasis. J Tradit Complement Med. 2016;6:395-8.

30. Richards HL, Fortune DG, Griffiths CE. Adherence to treatment in patients with psoriasis. J Eur Acad Dermatol Venereol. 2006;20:370-9.

31. Zaghloul SS, Goodfield MJD. Objective assessment of compliance with psoriasis treatment. Arch Dermatol. 2004;140:401-5. 